\title{
Construir um viver junto na democracia renovada*
}

Jean-Jacques Schaller

Université Paris 13

Correspondência:

Jean-Jacques Schaller

Université de Paris 13

UFR Lettres, Sciences de I'Homme

et des Sociétés

Av, J-B Clément 93430

Villetaneuse

e-mail: schaller@|shs.univ-paris13.fr

* Este texto serviu de base para duas conferências realizadas na Faculdade de Educação da Universidade de São Paulo, em novembro de 2001, no âmbito do projeto de cooperação internacional CAPES/COFECUB intitulado "A Gestão da violência e da diversidade na escola". Tradução do original francês Construire un vivre ensemble dans une démocratie renouvelée, por Maria Teresa Vianna Van Acker.

\section{Resumo}

Como construir um viver junto entre iguais e diferentes em uma democracia na qual os indivíduos beneficiam-se de direitos que os protegem da onipotência dos aparelhos de conformação cultural? Neste artigo, democracia é definida como o respeito aos direitos do homem e da pessoa contra a usurpação desses aparelhos. É o regime da liberdade de expressão, da liberdade de associação. É um espaço de liberdade de consciência para as pessoas e um espaço para o direito das minorias. Trata-se de favorecer a construção do Sujeito na tensão entre uma identidade integrativa e uma identidade conflitual, indicando que qualquer reconhecimento da ação do ator passa por sua inscrição em uma relação social.

A criação dos espaços de debate pelo próprio agente permitirá questionar seu distanciamento das condições de produção de sua vida. Esses espaços de debate remetem à necessidade, no seio de uma sociedade em transformação, de favorecer os domínios da aventura, os lugares de vida e não os lugares para vida. Onde o Outro tem seu lugar, e o mais longe possível da violência que quer reduzir o Outro ao mesmo. Trata-se de criar novas relações sociais pelo debate, fator de desdramatização do cotidiano, tendo como ponto central a capacidade de cada um produzir sua própria vida.

\section{Palavras-chave}

Democracia - ldentidade integrativa - ldentidade conflitual - Espaço de debate. 


\section{Building relations in the renewed democracy*}

Jean-Jacques Schaller

University of Paris 13

\section{Correspondence: \\ Jean-Jacques Schaller \\ Université de Paris 13 \\ UFR Lettres, Sciences de I'Homme \\ et des Sociétés \\ Av, J-B Clément 93430 \\ Villetaneuse \\ e-mail: schaller@Ishs.univ-paris13.fr}

* Este texto serviu de base para duas conferências realizadas na Faculdade de Educação da Universidade de São Paulo, em novembro de 2001, no âmbito do projeto de cooperação internacional CAPES/COFECUB intitulado "A Gestão da violência e da diversidade na escola". Tradução do original francês Construire un vivre ensemble dans une démocratie renouvelée, por Maria Teresa Vianna Van Acker.

\begin{abstract}
How do we - equals and different - build relations in a democracy in which individuals benefit from rights that protect them from the omnipotence of the apparatuses of cultural conformation? Democracy is here defined as the respect for human and personal rights against the usurpation promoted by those apparatuses. It is the regime of freedom of expression, of freedom of association. It is a space for freedom of consciousness for people, and a space for the rights of the minorities.

It is about promoting the construction of the Agent in the tension between an integrative identity and a conflictual identity, pointing out that any recognition of the actor's action relies on its insertion in a social relation.

The creation of spaces for debate by the actor will allow him to question his distancing from the conditions for the production of his life. Those spaces for debate remind us of the need, in the middle of a society in transformation, of promoting the domains of adventure, the places of life, and not the places for living, where the Other has its place, and the farthest from the violence that wants to reduce the Other to the same. Through debate, a factor of de-dramatization of everyday life, one deals with the recreation of the social relation having at its center everyone's ability to produce his/her life.
\end{abstract}

\section{Keywords}

Democracy - Integrative identity - Conflictual identity - Space for debate. 
A convivência entre iguais e diferentes não é a principal questão do século XXI?

A globalização, por intermédio dos aparelhos de conformação cultural, une a todos nos mercados de consumo e de informação... mas em que isso nos reaproxima do Outro? Ao contrário, alguns de nós buscam refúgio na própria identidade, recorrendo à defesa de uma comunidade homogênea que produz essencialmente a rejeição de qualquer Outro, percebido como ameaça. A violência é a vontade de querer reduzir o Outro ao mesmo!

A questão é, justamente, combinar uma participação no mundo, notadamente científica e técnica, com a possibilidade de afirmar sua herança cultural e sua história pessoal. Essa produção de si não pode realizar-se no isolamento ou no afastamento, deve, porém, ser construída defrontando-se, ao mesmo tempo, com a dominação do mundo dos mercados e com as falsas promessas comunitárias; reconhecendo ao Outro, assim como a si mesmo, o direito de ser Sujeito e pondo a democracia a serviço da liberdade criativa de cada um e da construção de uma solidariedade coletiva.

Como, então, posso comunicar-me com os outros e viver com eles? Como podemos combinar nossas diferenças com a unidade de uma vida coletiva?

\section{A realidade social não é mais totalidade}

A realidade social muda e, com ela, a idéia que fazemos dela. De meados do século XIX até os anos 1950, os sociólogos, quaisquer que fossem suas diferenças, pensaram a sociedade como uma totalidade: um elemento coerente, congruente com a revolução industrial e a formação dos Estados-nação democráticos modernos, cujo princípio de organização residia, segundo as teorias, na estrutura das relações de classe, no sistema de instituições, no empreendimento da cultura. Ora, a bela unidade dessas análises está fendida: diante dos fatos e sob o efeito das críticas e inovações teóricas, “o projeto de conseguir uma representação do conjunto da vida social a partir de algumas noções unitárias e centrais se desfez" (Dubet; Martucelli, 1998).

Devemos, então, nos acomodar com o esfacelamento das perspectivas de análise (da sociologia) e, por fim, abandonar a idéia de sociedade? De forma alguma, pois isso seria renunciar à inteligibilidade do que, apesar de tudo, nos une. Se a tarefa, atualmente, não é mais construir uma visão ordenada em torno de um eixo congregante, é importante analisar a pluralidade e a heterogeneidade das lógicas que orientam a "experiência social", por meio das quais se redefine um mundo comum. Reencontram-se, aqui, as três "lógicas da ação" - a estratégia, a integração e a subjetivação - em relação as quais François Dubet (1994) já havia enfatizado a autonomização e a desvinculação crescentes. Cada uma delas se desenvolve em uma esfera da vida social - o mercado, as instituições e as representações do indivíduo - esse é o ponto de partida que devemos tomar para isolá-las e construir um estado dos lugares.

A diminuição do trabalho industrial, as novas estratificações profissionais, a instabilidade do emprego, a precarização dos assalariados embaralharam as antigas fronteiras e referências. 0 movimento operário não pode mais ser considerado o motor principal da mudança social. E a análise em termos de classe não pode mais, sozinha, explicar a organização da sociedade e seus conflitos. Na verdade, a desarticulação das relações de produção e de reprodução gera novas desigualdades e novas formas de dominação que deslocam as linhas de clivagem. Os "competitivos", assalariados dos setores altamente produtivos, os "protegidos", essencialmente membros do serviço público, os "precários", empregados com contratos temporários e os "excluídos", mais ou menos beneficiários da proteção social, estão engajados em uma "luta por lugares" que suscita tensões, mobilizações e alianças móveis.

A escola, a família, as igrejas não são 
mais espaços de socialização e de integração, instâncias que asseguram a reprodução e a estabilidade da sociedade, fábricas ideológicas que permitem engendrar indivíduos, ao mesmo tempo autônomos e em conformidade com as exigências do sistema. Não se trata apenas de uma "crise" ou de uma desadaptação conjuntural dessas instituições, mas de um processo mais profundo de "desinstituciona-lização", ao termo do qual as normas e os valores não são mais percebidos como entidades pré-existentes que se impõem do exterior aos indivíduos. Simultaneamente desenvolve-se uma "cultura heróica do sujeito" que remete cada um à construção e à responsabilidade de seu próprio destino. As relações sociais são, dessa maneira, sentidas como uma série de provas individuais: é preciso ter desempenho, ser merecedor, motivado, tanto no mercado de trabalho quanto na escola e na universidade, ao passo que recursos e oportunidades são, evidentemente, distribuídos desigualmente. Isso engendra sofrimentos e sentimentos de não-reconhecimento e desprezo que são estopins da violência, especialmente no meio escolar. E, no hiato entre um individualismo promovido e uma dominação vivida, as reivindicações de identidade surgem de forma intensa, como possíveis refúgios.

Esse conjunto desarticulado, abandonado às múltiplas tensões, não está nem completamente desencantado, nem completamente atomizado. Ele reencontra uma espécie de unidade, continuamente redefinida e reafirmada, na dinâmica dos movimentos sociais, nas cenas midiáticas do espaço público e no jogo democrático da vida política.

É aí que se "constrói, hoje, a idéia de sociedade, por meio de seus debates, seus conflitos, suas interpretações, suas capacidades de ação" (Dubet; Martucelli, 1998). Em resumo, ela é o que fazemos que ela seja, de maneira confusa, às vezes contraditória e freqüentemente aleatória. Essa constatação recusa a nostalgia tanto quanto a renúncia. Mas ela nos obriga a responder a pergunta: em que sociedade queremos viver?

\section{Sujeito e movimento social}

Retornemos ao âmago de nossas preocupações, ou seja, ao Sujeito: ao Sujeito como motor de novos movimentos sociais, ao Sujeito para lutar contra a idéia de uma dualização da sociedade, contra a idéia que a exclusão é um processo irreversível, significando, por isso mesmo, o fim de uma concepção da sociedade em termos de relações sociais.

Não retornemos à globalização das sociedades (Schaller, 1997). Retenhamos, entretanto, que esse mundo do mercado, quase sempre apresentado, ele também, como irreversível, por ser modernista, produz, sobre as populações mais modestas, o sentimento de que essa forma de desenvolvimento econômico se faz às suas custas e com a manifestação de posições populistas e xenófobas, de contrapeso. Efetivamente, para toda uma parcela das camadas médias, o essencial é não ser lançado na exclusão.

A partir do momento em que uma sociedade deixa de ser estruturada por um conflito como aquele conduzido pelo movimento operário, a partir do momento em que essa sociedade não pode mais ser pensada como integrada pela existência de instituições que asseguram a cada um o processo de socialização e chances de mobilidade social ascendente, entramos em uma sociedade que, em seu desenvolvimento inicial, produz a dualidade da qual a exclusão é uma realidade incontestável.

Alain Touraine mostrou que o surgimento do fenômeno da exclusão marcava uma ruptura histórica:

Ontem, ainda, procurávamos definir, para compreender uma sociedade, suas relações sociais de produção, seus conflitos, seus métodos de negociação; falávamos de dominação, de exploração, de reforma ou de revolução. Hoje, só falamos de globalização ou de exclusão, de distância social crescente ou, ao contrário, de concentração do capital ou da capacidade de difusão das 
mensagens e das formas de consumo. Tínhamos o hábito de nos situarmos, uns em relação aos outros, a partir de escalas sociais, de qualificação, de renda, de educação ou de autoridade; substituímos essa visão vertical por uma visão horizontal: estamos no centro ou na periferia, dentro ou fora, na luz ou na sombra. (Touraine, 1997)

Nesse esquema, o indivíduo que está fora não tem mais, como no caso de uma sociedade de integração piramidal, a possibilidade de imaginar que possa subir os degraus da escala, que possa progredir e se sair bem 0 fosso aparece como algo quase intransponível e o medo difuso é o de cair do lado errado. "Éramos uma sociedade de discriminação, tornamo-nos uma sociedade de segregação" (Touraine, 1991). Essa sociedade segregativa produz a patologia social na qual as populações são tomadas como prisioneiras das transformações econômicas e sociais, das situações sociais das quais não se assenhoreiam. Aqui transparecem as imagens da não-ação, do absurdo das condutas dos atores.

Essas imagens de vitimas sociais remetem, também, a uma defectologia individual. 0 processo segregativo mantém uma abordagem integrativa, um apelo à identidade integrativa como uma referência a um sistema normativo central: para pertencer à sociedade, é preciso estar dentro. Os outros não contribuem para a vida econômica, não participam da vida cultural e social. A segregação marca toda uma população definida por uma distância em relação a essa norma central de integração. Essa distância pode ser caracterizada, seja em termos de participação social, ao descrever toda uma população como inutilizada, seja em termos de valores morais, nos quais os comportamentos das pessoas são descritos como fora das expectativas sociais

A passagem da sociedade industrial à sociedade pós-industrial vê a produção ser substituída pelo consumo. Esse consumo não é tanto o de produtos manufaturados quanto o de produtos culturais que conformam nossas personalidades. Participar dessa sociedade em construção é depender da participação nos fluxos de trocas de informações, dos signos de pertença. Donde decorre o desenvolvimento do individualismo como um "dever ser considerado pelos outros". Para ser reconhecido é preciso estabelecer o seu lugar, é preciso tornar-se o vendedor de sua própria vida. Parafraseando De Gaulejac (1994), para existir, para ser reconhecido, é preciso ser útil e produtivo. É nesse sentido que ele fala em "luta de lugares", substituindo a "luta de classes". A luta de lugares é uma luta solitária de cada indivíduo face à sociedade para se fazer aceitar, para existir, ou seja, viver e se fazer reconhecer como um cidadão por inteiro.

Se o patrão e o operário eram as figuras emblemáticas da sociedade industrial, hoje, sempre de acordo com De Gaulejac, são o executivo e os beneficiários da renda mínima de inserção (RMlstes) que se tornaram os arquétipos da sociedade pós-industrial. De um lado, a identidade positiva do executivo que encarna o sucesso, a promoção, o dinamismo, o desempenho, a competência, a valorização, a facilidade e a riqueza. Do outro, o RMlste, como protótipo da identidade negativa, do fracasso, da regressão, da passividade, da decadência, do trabalho precário, da incompetência, da desvalorização, da mediocridade e da pobreza.

A luta dos lugares confronta a pessoa em situação de dificuldade com uma imagem negativa que estabelece uma contradição entre o que lhe é necessário ser para se fazer reconhecer socialmente e a identidade que lhe é atribuída. 0 desempregado, o desvalido sem domicílio, o inativo sem utilidade, o exilado sem pátria, o prisioneiro a quem se nega o nome ao se chamar por uma matrícula, o imigrante sem direito... são todos definidos por uma falta.

É essa falta que se torna o principal elemento da identidade social deles. Eles têm o sentimento de que sua existência é recusada, que precisam ser diferentes de seus semelhan- 
tes, ou seja, de todos aqueles que partilham a mesma condição e que são socialmente invalidados.

É verdade que a exclusão encoraja “em certa medida, condutas defensivas que podem desembocar na raiva, na violência, eventualmente autodestrutiva, na apatia, no ensimesmamento ou no isolamento, ou ainda em um fechamento identitário ou em uma heteronomia política" (Dubet, 1987).

Em um plano mais geral, a questão, a minha questão, é exatamente compreender as forças sociais e culturais que podem contribuir para a recomposição desse mundo dualizado. Posição de pesquisa do sociólogo que é a de se interrogar sobre as capacidades de ação das pessoas em situação de dificuldade e, sobre o sentido de suas condutas diante de um sistema de situações sociais. Posição de intervenção do sociólogo desejando chegar a uma tentativa de proposta, até mesmo de experimentação, de práticas de intervenção que, sustentadas pelos desafios desmascarados no nível da análise da produção da marginalidade, tentam balizar a construção de modelos inovadores e até acompanhar as transformações sociais atuais e restituir aos atores - populações marginalizadas e profissionais do social - suas respectivas capacidades de ação, em direção à construção de um novo viver junto em uma democracia renovada.

A mobilização do sujeito como ator do movimento social deve poder construir-se com base em espaços sociais que abram o caminho para uma possível conflituosidade. Essa posição de conflito passa pelo reconhecimento dos "excluídos", mas deve igualmente mobilizar os “incluídos” na interpelação dos aparelhos de conformação cultural.

0 essencial, por ora, é não confinar os excluídos na sua miséria e na sua patologia, o que impede qualquer consideração sobre o que a pessoa diz em situação de dificuldade. Ela está reduzida ao silêncio no absurdo. Isso the nega toda a capacidade de ação. É preciso, portanto, inverter esta percepção do funciona- mento social em termos de defeito de integração social para, ao contrário, centrar na perspectiva dos necessários conflitos sociais e conclamar à renovação dos processos democráticos.

Isso significa que, por trás da descrição dos processos de integração/exclusão, a violência das relações de dominação deve ser desmascarada. 0 movimento não é um dado, ele se constrói e cada um, "incluídos" e "excluídos”, deve ser levado em conta no necessário debate coletivo cujo desafio é exatamente a luta contra a marginalização e pela solidariedade.

A pessoa em situação de dificuldade, ao recusar ser reduzida a uma situação de exclusão, prioriza a questão do reconhecimento e, portanto, da prioridade da relação social que dá o direito a cada um de "viver sua vida". "O Sujeito está na vontade de um indivíduo de agir e de ser reconhecido como um ator" (Touraine, 1992). Trata-se, para o Sujeito, de se construir como indivíduo total cujo particularismo, a ação e a palavra caracterizam a humana condição. Poderíamos dizer que estamos todos no mesmo barco! Em busca de existir, de criar sua vida, de exprimir sua palavra, uma palavra diferente, até mesmo contestatória.

Como o Sujeito, por meio de sua ação, pode articular o que ele é, o que gostaria de ser, ou seja, produzir sua vida? A ação do Sujeito está contida nessa vontade de transformar seu espaço, de criar sua história, de dar um sentido ao conjunto de suas experiências de indivíduo. Viver sua vida é exatamente encontrar nela um sentido que esclareça as condutas individuais e coletivas.

Como fazer a passagem dessas formas de mobilização individualizada para uma ação coletiva contestatória? Como ligar a reivindicação de particularismos à contestação de uma relação desigual?

A pessoa em situação de dificuldade só pode agir combinando orientação cultural e relações de dominação. Isso passa pela construção de um ponto de vista autônomo e de um espaço exterior à dominação cultural de onde 
ele poderá contestá-la. Tal procedimento implica um esforço de conformação que ultrapassa o simples tratamento da dificuldade social para se engajar em uma dinâmica de reinscrição da pessoa nas relações sociais. 0 que está aqui, posto em evidência, é a relação entre a análise e a ação.

Eu proponho uma articulação entre pesquisa/intervenção/ação. Tomando o termo intervenção como o conjunto dos dispositivos que permitem articular a relação pesquisa/ação. E se o objeto central é interrogar-se sobre a capacidade de ação das pessoas em situação de dificuldade, e sobre o sentido de suas condutas perante um sistema de situações sociais, então, esse objeto pode recair sobre os meios de intervenção passíveis de favorecer uma reapropriação da capacidade de ação da pessoa. Trata-se de situar o ponto de vista da análise do lado do ator em situação de dificuldade que se interroga sobre o que ele pode produzir, construir, para ser reconhecido como ator social.

$\mathrm{Na}$ França, promover modos de intervenção social que respondam à necessidade de apresentar como centrais as preocupações da pessoa em dificuldade transformou-se em um verdadeiro slogan: dos aparelhos de Estado, dos organismos de saúde às grandes associações nacionais de ajuda mútua, todos adotaram esse indispensável posicionamento do cliente como centro de suas ações. Para mim, situar a pessoa no centro de um projeto de intervenção significa, então, levar em conta as conseqüências individuais que "sua dificuldade" produz, e igualmente, os fatores de produção de suas condições sociais. Não se trata de situar a pessoa no centro de um dispositivo, mas estar centrado sobre a pessoa em situação de dificuldade. Trata-se exatamente de favorecer uma concepção de integração social da pessoa em uma abordagem na qual a diferença, ao invés de ser negada, é considerada como parte integrante do funcionamento social e deve ser integrada ao conjunto das condutas que definem o campo das relações sociais.
0 que deve ser reconsiderado é "o distanciamento radical que separa, no cotidiano [regulado pelo mundo do mercado, ou seja, a produção para o lucro], o produtor e as condições sociais da produção de sua vida" (Lucas, 1978). Trata-se, exatamente, de uma reivindicação de democracia: pôr em foco a capacidade de cada um produzir sua vida.

Detenhamo-nos, um pouco, na noção de democracia.

Apoiando-nos em uma tipologia proposta por Dubet (1994), podemos determinar três concepções clássicas.

A primeira é de ordem contratual. A democracia define os direitos e os deveres dos cidadãos que partilham uma parcela do poder e que, pelo viés da nação, constroem uma comunidade política. A democracia define o que os membros de uma comunidade política têm em comum, o que os faz cidadãos de uma mesma nação. A finalidade dessa democracia é a integração de uma sociedade de indivíduos que renunciam uma parte de sua individualidade em nome da sociedade política. A democracia é nacional. Os cidadãos são sempre os agentes de uma nação, os membros de uma comunidade de indivíduos unânimes porque são cidadãos buscando encontrar uma vontade geral.

A segunda concepção é de ordem representativa. A democracia é definida como a representação legal e pacífica de interesses opostos, reconhecidos e aceitos. A democracia é o sistema que transforma as oposições sociais em rivalidades políticas legais. Ela é concebida como um modo de participação concorrencial na tomada de decisão. Essa democracia implica que, através de forças sociais - partidos, sindicatos, associações -, os interesses concorrentes enfrentem-se segundo regras estabelecidas. A democracia representativa é censitária, ela é uma oligarquia eletiva e elitista; nem todos os cidadãos votam, e nem todos os interesses estão representados.

Enfim, a última concepção é de ordem universalista. Aqui, os indivíduos beneficiam-se dos direitos que os protegem da onipotência do 
Estado, das igrejas e das instituições. A democracia é, então, definida como o respeito aos direitos do homem e da pessoa contra as impiedades daqueles aparelhos. É o regime da liberdade de expressão, da liberdade de associação. É um espaço de liberdade de consciência para as pessoas e um espaço para os direitos das minorias. Não é necessário que os indivíduos sejam cidadãos e eleitores para que essa dimensão democrática esteja presente, mas não há democracia sem ela.

A democracia do contrato dos cidadãos define politicamente os laços de solidariedade e de identidade A democracia representativa constrói um mercado de rivalidades e de influências políticas. A democracia dos direitos do indivíduo define o espaço daquilo que é autônomo, respeitável, autêntico e sagrado em cada um, quer seja ou não cidadão, quer esteja ou não representado. (Dubet, 1994)

0 trabalho de um sistema político democrático consiste em articular essas concepções, da mesma maneira que o trabalho do ator individual consiste em dar sentido à produção de sua vida.

Dessa tipologia retemos que uma democracia não é uma simples participação política. Ela não é uma tolerância pura, nem a afirmação de uma cidadania separada das relações sociais desiguais da sociedade. A democracia é a política do sujeito,

quer dizer, a busca da participação da maioria, dos indivíduos e dos grupos, os mais diferentes possíveis, nas mesmas atividades e com as mesmas regras de organização, mas também, e principalmente, com as mesmas formas de reconhecimento do outro. (Touraine, 1995)

A democracia é o conjunto de instituições que permitem o mais alto nível possivel de reconhecimento do outro.
Trata-se, pois, de criar as condições sociais que permitam a cada pessoa ter acesso, com sua particularidade, à cidadania e à construção de "sua" vida. Isso implica a absoluta necessidade de reconhecer a pessoa por trás do excluído. É preciso reconhecer o Sujeito com seu direito ao respeito, à dignidade, porém, mais ainda, que esse Sujeito, na sua vontade de agir como um ator, possa influenciar as condições sociais que lhe permitem existir enquanto tal, como uma pessoa por inteiro, que contribuiu, ela também, na construção da sociedade.

As condutas da pessoa em situação de dificuldade são compreendidas ainda como formas de contestação e de reivindicações ante os aparelhos que impõem uma conformação cultural da definição de si mesma. 0 movimento social passa, então, pela expressão das reivindicações das pessoas, das minorias em situação de dificuldade por meio da criação de espaços de debate associada a um procedimento de reforço da democratização da vida social.

A democracia significa "reconhecimento" de todo indivíduo particular como um ator político devendo ser respeitado e entendido na sua particularidade. Ela é reivindicada em si mesma, definida cada vez mais em termos culturais de igualdade de condições. Nesse sentido, ela significa a reivindicação de uma cultura permitindo a cada um viver sua vida e “ser o que é". (Lapeyronnie, 1995)

A democracia deve permitir a cada um ser um cidadão "que tende para as diferentes modalidades da convivência” (Schaller, 1999), em um debate sobre nossas condições de vida e, por isso mesmo, sobre nossos projetos.

Gostaria de retomar o conjunto dessas proposições tentando articulá-las com duas questões complementares. Aquela da relação entre a identidade integrativa e a identidade conflitual, dupla face da construção do Sujeito, e aquela da necessária construção de espaços 
de debates como expressão de uma democracia renovada. A abordagem dessas duas questões se apoiará sobre experiências inovadoras no quadro das intervenções médico-sociais.

\section{Identidade integrativa, identidade conflitual}

Para ilustrar essa questão, vou me apoiar na análise limitada de uma experiência de mediação por meio do livro.

Em 1990, os serviços do Ministério da Cultura, que há dez anos haviam feito acordos com a rede de bibliotecas de rua (na França, elas são uma centena), posta em prática pela associação ATD Quart Monde, ${ }^{1}$ engajam-se em qualificar para a mediação por meio do livro quinze jovens apresentados essencialmente por essa associação. Essa formação teve início, concretamente, em 1992, e durou por um período de dois anos. Sua realização foi garantida por ISIS CREAl île de France ${ }^{2}$ e pela Associação dos Bibliotecários da França.

A mediação por meio do livro é compreendida como a ação de tornar a leitura e o livro conhecidos desses que estão excluídos - principalmente os jovens - fora das paredes da biblioteca e em contato com os novos parceiros. Os "mediadores do livro" nos bairros, cada um deles com o apoio de um tutor associado, têm, então, a tarefa de se aproximar do público mais excluído da cultura e familiarizá-lo com o mundo do livro e das bibliotecas. Para isso eles trabalham como animadores, especialmente nas bibliotecas de rua dos bairros desfavorecidos, são a ponte entre as populações mais distantes do livro e as instituições, os aparelhos culturais.

Eles também têm o objetivo de fazer com que essas instâncias culturais possam mudar suas práticas em relação a essas populações, portanto, transformá-las para que elas cumpram sua missão junto a um público mais amplo, sem exclusividade.

\section{o lado positivo?}

É a dinâmica do saber compartilhado. Essas ações de mediação têm por objetivo construir elos com as crianças e suas famílias, por meio dos quais os mediadores do livro compartilham seus conhecimentos e seus prazeres e, ao mesmo tempo, ensinam as crianças e os seus pais.

Trata-se de um verdadeiro saber-fazer, o de mediador do livro. É preciso escolher lugares adaptados; respeitar a regularidade dos encontros; levar livros de qualidade. As histórias serão próximas do que as crianças e os jovens vivem para permitir uma identificação, ou, ao contrário, plenas do maravilhoso, abertas para um outro universo. É preciso estar atento para a criança em maior situação de dificuldade, essa é a criançareferência, a criança-alvo, que deve poder quebrar a espiral da exclusão.

Temos aí todas as dimensões de um discurso de socialização em direção das populações excluídas do mundo dos valores dominantes. 0 mediador é, aliás, freqüentemente, definido como o intermediário, o negociador, o árbitro, o conciliador. 0 mediador é aquele que constitui o elo entre dois mundos. Mas quais dois mundos?

\section{O lado negativo?}

Encoberta por essa experiência de mediação, não se pode falar, como o faz Dubet (1998) de uma situação de "tipo colonial"? Ele entende por isso que a distância entre o usuário e o trabalhador social se define em termos de "civilização" e de "barbárie" e que, como sempre nas situações coloniais, o grande problema é encontrar os intermediários, as pessoas suficientemente civilizadas para falar aos bárbaros o que dizem os colonizadores e fazer os colonizadores que administram o local entenderem a língua dos bárbaros. De fato, os trabalhadores sociais não vivem mais nos mesmos

1. ATD Quart Monde, (Auxílio a Todo Desalento Quarto Mundo; Associação carismática).

2. ISIS CREAI le de France é um importante Instituto de formação dos trabalhadores sociais em Île de France. 
lugares em que essas populações vivem, nem trabalham mais nos bairros difíceis. É preciso encontrar os animadores oriundos desse meio.

Os educadores, no sentido mais amplo - professores, bibliotecários -, desistem, alguns se recusam a falar com "essa gente", "essas crianças". Inventam-se os mediadores, o que tem como efeito conferir um caráter excessivamente étnico aos problemas. A análise das condutas das pessoas marginais não remete a sua situação social em termos de relações sociais, mas apenas à dimensão étnica: se essa criança tem problemas de integração na cidade, de integração na escola, é porque ela é de Mali. Donde, cada vez mais, da parte do conjunto das instituições de socialização há uma certa lógica do não-encontro, do não-confronto.

Como dizia Bachmann (1998), o trabalho social ${ }^{3}$ tornou-se uma função encantatória, com algumas palavras fetiches (mediação, inserção, projeto, parceria, avaliação) em total descompasso com o vocabulário "indígena”, o que induz a uma crise de credibilidade da política pública. Para ultrapassar esse esquema colonial, é preciso invocar o conceito de identidade do sujeito.

A sociologia da ação, à qual eu me refiro, é inimiga do eu. É preciso salientar que a consciência que o ator tem de si mesmo não restitui o sentido de sua situação, a razão de ser de suas condutas. Essa é uma das ilusões da identidade.

A identidade social, então, é apenas uma interiorização dos valores e esses não são separáveis da ideologia dominante de uma sociedade. Alguém pode sentir-se marginal e reconhecer que ocupa uma posição baixa na escala de reivindicações, de nível profissional, de educação, de influência. 0 que significa essa consciência senão o reconhecimento de uma ordem estabelecida e a ocultação dos fundamentos dessa ordem, das relações de dominação, de poder ou de exploração?

Os métodos de socialização, de educação, completam a obra das instituições, eles ensinam o ator a adaptar-se à sociedade, a reconhecer seu lugar nela, a compreender as regras do jogo para utilizá-las o melhor possível. Está exatamente nisso o lado luminoso dessa experiência do mediador do livro. Todavia, quanto mais o ator se define pelas suas práticas e suas relações sociais, mais ele é tomado pela consciência de privação e de dependência, pela ausência de comunicação, arbitrio e poder. A identidade se impõe de fora. Ela não diz quem eu sou e o sentido do que eu faço, mas quem eu devo ser e as condutas que se espera de mim, sob pena de sanção. A identidade só pode ser a submissão dependente, heterônoma e alienante em relação a um poder. Para poder devolver sentido ao conceito de identidade, é preciso acoplá-lo às outras duas componentes que definem a ação: a oposição e a totalidade.

A formação da identidade social só é possível se a ordem social não aparecer mais ao ator como um sistema impessoal, mas como obra dos homens, como projeção de relações sociais, por meio das quais uma sociedade dá forma à empresa da historicidade ${ }^{4}$ sobre as práticas sociais. Ao invés de partir da ordem estabelecida, dos valores e de suas normas, de sua definição dos status e papéis, devemos partir da dialética da ação histórica.

A identidade não nasce somente da consciência das contradições, mas também da busca do controle da transformação social. A busca da identidade não é um comportamento reflexivo, nem a descoberta das coordenadas sociais, do status e dos papéis assumidos; ela é o nascimento de um movimento social, ela é o nascimento do movimento do sujeito. É por isso que propomos duas faces desse conceito para torná-lo operacional nas pesquisas, espe-

3. 0 trabalho social é um conjunto de intervenções em relação a pessoas ou grupos em situação de dificuldade a título de políticas sociais (públicas ou privadas) desenvolvidas em um país.

4. Historicidade é o nível da análise sociológica no qual a sociedade é considerada como produzindo-se por si mesma. Aqui, tenta-se descrever os instrumentos de produção da sociedade em termos de modelo de acumulação, de modelo de conhecimento e de modelo cultural. Os atores estão em posição de conflito dada a relação de dominação. 
cialmente, no campo da educação.

Priorizamos a necessidade de pôr em evidência uma identidade integrativa e uma identidade conflitual. A identidade integrativa indica o nível de interiorização que cada ator tem de um sistema social dado. A identidade conflitual do ator visa, ela sim, a uma ordem, uma dominação e não apenas a uma simples definição de si.

Assim, pensamos que uma busca de integração passa pela mediação da inscrição dentro de um conflito, na busca expressiva da relação social. Essa abordagem teórica implica pedagogicamente em dar prioridade à identidade conflitual sobre a identidade integrativa. É pelo conflito que o ator Jovem - nesse caso da experiência de mediação pelo livro - torna-se apto a se construir e a se integrar. A anomia, a frustração, a exclusão, a violência e a raiva não podem, então, ser tomadas por simples explosões espetaculares da ação dos jovens dominados ou marginais ou como puras reações de crise. Essas manifestações são, ao contrário, as asperezas às quais ele precisa se prender para compreender as formas de ação social ligadas à transformação das relações sociais.

Nossa questão diante dessa experiência dos mediadores do livro permanece a mesma: os procedimentos de acesso ao livro que foram estabelecidos serviram para reforçar uma posição de normalização das condutas que devem ser desenvolvidas pelas populações em um sistema social dado ou, ao contrário, permitiram uma abertura à expressão das demandas do Sujeito?

\section{Espaço de debates e democracia renovada}

Uma abertura à expressão de demandas do Sujeito.

Vou retomar essa questão me apoiando sobre uma experiência antiga, de vinte anos atrás, que fundamenta em grande parte a noção do espaço de debates à qual sou tão ligado. 0 ponto de partida foi uma experiência que deve ser qualificada de antipsiquiátrica e que foi desenvolvida nos anos 1975/1980 em uma cidade tão particular como é Montceau-lesMines. ${ }^{5}$

Naquela época, Montceau-les-Mines de certa forma ainda era uma cidade mineira,mas era também, sem nenhuma dúvida, uma cidade psiquiátrica. Ela fora concebida para ser anticasebres, antifavelas, construída como uma cidade de saúde, regida por um pensamento higienista empenhado na prevenção contra os efeitos patológicos do adensamento, da doença, do crime. É a mesma história que subjaz à construção da prisão de Santé, ${ }^{6}$ em Paris. Lá também se caçavam os humores criminosos por um olhar adaptado à prevenção e ao controle de comportamentos a serem normalizados.

Montceau-les-Mines, então, com suas sucessivas fileiras de casinhas ao longo de ruas retas e largas... A essas imagens fortes do paternalismo industrial, próprio ao meio mineiro, pode ser oposta uma outra imagem, a de uma Montceau-les-Mines, grande hospital psiquiátrico. Essa cidade o é, seguramente, pela distribuição hierárquica do espaço. Privilégios tais como venezianas nas janelas, banheiros internos, sobrados, são objetos de uma divisão minuciosa que permite, ao primeiro olhar, identificar e distinguir as casas do operário mineiro, do contra-mestre ou do chefe dos contramestres, sabendo que o engenheiro-chefe tem direito a uma casa maravilhosa com vasto jardim e jardineiro encarregado.

Diga-me onde moras e direi a profissão de teu pai...

5. Esta experiência não pretende ser apresentada como modelo. Sua lógica é aquela de uma prática cotidiana marcada pela violência do trabaIho nas minas de carvão, pela força das coisas: esses sofrimentos cotidianos que cortam as palavras e que se inscrevem nos corpos. Essa experiência tenta inventar como compreender, e não apenas escutar, com o objetivo de ter uma idéia de todas as formas de intervenção suscetíveis de modificar o mal que ocupa o corpo do Sujeito e da Cidade.

6. Prison de Santé. 0 nome dessa prisão parisiense insere-se na vontade higienista do século XIX. É a primeira prisão na França onde os arquitetos trabalharam com a circulação do ar para evacuar os "humores criminais". As prisões anteriores a ela prendiam os detentos em celas sem circulação de ar, sem luz. 0 termo saúde quer dizer aqui que os detentos, que são doentes, encontram uma "saúde" visto que o ambiente e a regra do cárcere afugentam as doenças criminais 
Hierarquizado, o espaço de Montceaules-Mines foi organizado e concebido para o olhar, até mesmo pelo olhar: um olhar médico que não necessariamente aquele do corpo médico, mas aquele do Outro. Esse espaço se oferece à primeira vista à vigilância mútua, às fofocas. As fofocas são uma manifestação da síndrome de Montceau-les-Mines: uma dor não localizada, uma doença que só se pode reconhecer.

A fórmula Montceau-les-Mines hospital psiquiátrico não é uma simples alegoria. É uma espécie de imaginário médico na escala de uma comunidade urbana construída sobre a ficção segundo a qual o que é estrago externo - os casebres da indústria nascente - pode ser reparado, regenerado pela colina ensolarada de Montceau-les-Mines e seus telhados de telhas vermelhas das cidades dos Chagot, a família proprietária das minas de carvão. Contradição entre a celebração constante do comedor de carvão, da boa mãe de família, dos bons filhos diante da suspeição latente da doença... Por isso uma delegação na qual o médico, o trabalhador social, recebe a missão da Sociedade (aqui, mineradora) de refazer o que ela desfez. E assim o paciente entrega-se às mãos de profissionais.

Mas "não se pode administrar a vida das pessoas! Por trás dessa constatação não há apenas impotência (não é possível administrar a vida das pessoas); há uma recusa (não temos que administrar a vida das pessoas)" (Lucas, 1978). Essa recusa é a do querer ordenar as condutas das pessoas conforme o modelo pronto para usar da nosografia; é a recusa da cultura do diagnóstico. É nessa recusa que se constitui a experiência de Montceau-les-Mines, por intermédio do trabalho dos profissionais dirigidos por Albert Jakubowicz, novo psiquiatra que chegou em 1975 ao serviço de psiquiatria da Sociedade de auxílio de Blanzy. ${ }^{7}$ As diferentes etapas de sua experiência (constituição dos grupos de doentes, trabalho de bairro, relações com organizações sindicais e políticas) vão permitir a emergência, para mim, da noção de espaço de debates.

A recusa do diagnóstico não visa somente o ato médico, mas toda uma cultura do diagnóstico sobre a qual uma "organização especializada" assenta seu saber manifesto. "Ao querer tratar o sintoma, rejeita-se a criança”, nos diz Mannoni (1985). Essa recusa procede igualmente de uma crítica que visa o caráter ilimitado da busca de si. Uma busca que "revela-se facilmente frustrada [por ser] uma busca de vida e de abolição da morte" (Rosolato, 1971).

Trata-se de pôr do avesso o movimento que conduz o paciente à "organização especializada", no sentido de que os objetos de cura não devem ser mais aqueles sobre os quais se dá, habitualmente, o processo de medicação. É necessário, ao contrário, pôr no centro da troca todos os objetos da vida cotidiana - a escola, o trabalho, a casa, a família, o amor todos os objetos que, uma vez recuperados, autorizam o paciente a exercer uma atividade de sujeito na medida em que ele deixa de ser objeto de manipulações com finalidade terapêutica [no sentido da definição de terapeuta dada por Goffman (1975).

0 que deve ser articulado, já dissemos, é a capacidade de ação do ator com as condições sociais de produção de sua vida.

É necessário, portanto, projetar dispositivos que procurem combater as condições do fracasso, as resistências, as frustrações. Os "grupos de doentes" participam dessa vontade. Trata-se de substituir a distribuição nosográfica dos agrupamentos, segundo o que uns e outros designam como seu sofrimento e, até mesmo, a origem desse. Uma série de grupos foi constituída: grupos de mineiros de carvão, de mulheres, de adolescentes, de traumatizados cranianos. A característica deles é serem absolutamente heterogêneos quanto ao diag-

7. A Sociedade de auxílio de Blanzy intervém na cidade de Montceau-lesMines. As sociedades de auxílio mineiras são reagrupadas em Uniões regionais e controladas por uma Caixa autônoma nacional no quadro do regime mineiro da Seguridade Social. Essas sociedades são historicamente muito anteriores à organização da Seguridade Social que data de 1945 
nóstico psiquiátrico (depressão, psicose, neurose). "De fato, empiricamente constituídos, com base na comunidade de discursos, os agrupamentos manifestaram, rapidamente, o que estava no princípio deles e no princípio das comunidades de discursos: comunidades de condições sociais" (Lucas, 1978).

É preciso apoiar a recusa a identificar a pessoa às suas condutas, formulando a hipótese de que por trás delas asfixiam-se aspirações que não encontraram oportunidade de se realizarem. Será preciso interessar-se pela pessoa em situação de dificuldade, pelo que ela é, além de seu sintoma.

A constituição dos "grupos de bairro" se origina nesse limite. 0 acesso dos curados a um discurso sobre sua doença e sobre a doença em geral, sobre a vida cotidiana (trabalho, lazer, moradia, escola, família, filhos, etc.) permite às pessoas que vão às consultas reencontrar um nível de autonomia. Todavia pareceu necessário transportar a estratégia agregativa ao coração da vida cotidiana: "nos bairros, onde se manifestam, ainda que ali não tenham se originado os males que conduzem a procura por consultas" (Lucas, 1978).

Tal iniciativa não implica apenas um deslocamento geográfico do consultório para os bairros, mas uma abertura para os que não vão às consultas. Decidiu-se, então, levar os problemas encontrados ao conhecimento dos militantes de diversas organizações sindicais e políticas para "debater com eles e instaurar com eles uma forma de cumplicidade".

É importante trabalhar aquém e além das condutas e não, simplesmente, a pessoa considerada como o maior problema. Tratase de se deslocar de uma atenção centrada sobre a pessoa para se posicionar sobre a situação social. Trata-se de correr o risco de querer recoletivizar um problema socialmente individualizado: remeter ao social, ao coletivo, um problema que foi individualizado, sobrecarregando pessoas mais sensíveis ou menos sólidas. Aquém e além das condutas.
Aquém, as práticas permitirão estabelecer a interpelação de todo mundo e cada um em particular. "Sobretudo não acreditemos que esses debates interessem apenas aos próprios drogados; trata-se de cada um de nós, pois nós somos sempre os desviantes de qualquer um”, pensa Touraine (1984).

Nessa perspectiva, trata-se de favorecer a criação, pelo ator marginal, de espaços-debates onde possa ser questionado seu distanciamento das condições de produção de sua vida. 0 desafio é exatamente um questionamento central dos mecanismos de produção da sociedade. Isso implica uma abordagem local, territorial das necessidades, da demanda da população marginal, do sofrimento, de sua história, etc., permitindo estabelecer com ela a análise de sua vida cotidiana. Apostar na análise dessa cotidianidade significa crer que, certamente, falar da impotência, do isolamento ou da dependência não basta para fazê-los desaparecer, mas os situa como transformáveis. Se há apenas o vazio, há a droga! É a inação que provoca a in-ação, a ação voltada para si.

Aquém das condutas, a abertura dessa cidade ganha então todo o seu sentido. "São nossos filhos" deveria poder dizer a cidade, mostrando sua sensibilização pelos problemas das pessoas em situação de dificuldade e transformando tal "drama" por meio da criação de uma necessária solidariedade de todos os cidadãos mediante o conflito, o compromisso.

0 que significa criar oportunidades, possibilidades, e que a cidade seja um vetor de mudança. Scatolero, criminólogo italiano, fala sobre essa situação em termos metafóricos:

"Dá-se a esse jovem pequenas moedas, elas são postas no seu bolso, ele não percebe as vezes em que recebe essa moeda. Mas, em um certo momento de sua vida, não se sabe quando, ele decide mudar sua vida, ele decide entrar na linha, neste momento, se puser as mãos no bolso, e encontrar a moeda, é mais fácil decidir mudar. Se não encontrar nada, é mais fácil ficar onde está” (Scatolero, 1985). 
Aquém das condutas, as práticas vão mobilizar um questionamento de todos e de cada um.

Além, à guisa de tratamento, haverá a orientação no sentido de uma responsabilidade coletiva ou de um projeto comum. Aqui, desvia-se do sintoma, deixa-se de invalidar a pessoa com uma série de "diminuições" que a fixam no tecido social e ela começará a ser questionada no seio de uma dinâmica coletiva. "Então, no momento em que um indivíduo está perdido, o grupo tem a responsabilidade de ajudá-lo a compreender, a reassumir-se ele mesmo, à sua maneira, e não pela força, como se deseja que ele se assuma. Mudar o homem. Em que isso consiste? lsso consiste em perguntar a cada um: qual é seu desejo? Seu desejo, falemos dele", escreve Dolto (1985). A violência, a droga e o álcool tornam-se, então, secundários, a partir do momento em que a pessoa integra-se em um projeto.

\section{Os espaços de debates}

Nessa perspectiva, trata-se de favorecer a criação, pelo próprio ator, dos espaços de debates nos quais possa ser questionado seu afastamento das condições de produção de sua vida, em que se possa articular, até mesmo se "desdramatizar" seu projeto, seus projetos.

0 desafio é exatamente um questionamento central dos mecanismos de produção da sociedade. 1sso implica uma abordagem local das necessidades, da demanda da população concernente, do seu sofrimento, de sua história, permitindo estabelecer com ela a análise de sua vida cotidiana. Apostar na análise dessa cotidianidade é crer que, seguramente, falar da impotência, do isolamento, ou da dependência não basta para fazê-los desaparecer, mas os coloca como transformáveis. É a inação que provoca a in-ação, a ação voltada para si.

"Trabalho político" (Lucas, 1978) no âmago de uma política da cidade, da urbe? Sem dúvida, ainda que este não seja mais carregado de "política" do que o trabalho clássi- co de conformação, geralmente, atribuído aos terapeutas [sempre segundo a definição de Goffman] e a outros trabalhadores sócio-sanitários. Mas, certamente de uma outra política.

Trata-se de criar espaços de debates que não se esgotem em querer reduzir a distância entre as normas e as condutas numa abordagem de conformidade, mas que, ao contrário, tentem projetar uma autonomia relativa entre as normas e as condutas. Esses espaços de debates remetem à necessidade, no seio de uma sociedade em transformação, de favorecer os terrenos da aventura, os lugares de vida e não dos lugares para a vida, os espaços de marginalidade reconhecida, de não inserção integrativa, onde o Outro tem seu lugar, e o mais distante possível da violência que desejaria reduzir o Outro ao mesmo.

À medida que os aparelhos de dominação cultural se desenvolvem, temos necessidade de espaços menos formais, até mesmo um pouco dissociados, onde a alteridade pode ser o motor de toda criatividade.

Nossa sociedade em transformação social, econômica e cultural deve reconhecer a necessidade de permitir que esses territórios indeterminados se desenvolvam em seu interior. E ante a problemática da exclusão, é desejável desenvolver zonas cinzentas, fracamente iluminadas, zonas relativamente indeterminadas quanto às normas e quanto aos julgamentos sobre as condutas, lugares onde o essencial não é mais reconhecer o bem e o mal e, por isso mesmo, querer sempre conformar. Não se trata de pretender criar um "novo paraíso". Trata-se de resistir a todo movimento de pura racionalização das práticas sociais e manter um claro-escuro e isso, para cada um de nós, marginais ou não.

Esses espaços de debates têm a intenção de serem engendrados em campo, onde se manifestam os sintomas, ou seja, a cidade na sua cotidianidade plural. Oferecer um espaço àqueles acusados pelas fofocas e aos outros a fim de que se instaure um debate sobre a "doença" - toxicomania, condutas de risco - 
sobre essa "coisa", para dar provas de que é possível falar disso, ao mesmo tempo, que é igualmente possível falar da vida, das envies $^{8}$, da solidão necessariamente inexorável, da dependência, da morte.

Nesses espaços de debates, é essencial-mente necessário "permitir aos diferentes elementos (eventos, experiências individuais ou coletivas, sensações, sentimentos, relações, julgamentos) trazidos por todos serem criticados, às contradições de se manifestarem, de serem sofridas" (Lucas, 1978).

Trata-se de "fazer aparecer e de descobrir os 'estados das coisas': a solidão, a velhice, o fracasso escolar, o tédio. Tantas coisas, das quais não é permitido falar" (Lucas, 1978) corriqueiramente. É muito pouco, se dirá. Não se corre o risco, ainda, de ser invadido por militantes organizados (políticos, sindicalistas) tentados a dominar esses espaços para levar sua palavra reivindicativa?

A experiência de Montceau-les-Mines sugere, no entanto, que esse "muito pouco" é diferente de nada. Se a palavra, nesse empreendimento, nunca desempenhou o papel terapêutico,

ela tem um efeito de demonstração, mais que um efeito de liberação: ao se falar de solidão, velhice ou impotência, demonstrase que é possível dizer o indizível, demonstra-se que aquilo de que se fala, porque se fala quando se deveria calar, ou seja, guardar para si, não é necessariamente nem meu segredo, "minha coisa", "meu problema", mas o segredo, a "coisa" que se deve calar. (Lucas, 1978)

No limite, salienta Lucas, retomando as proposições de Jakubowicz, médico psiquiatra em Montceau-les-Mines: "seria possível partir de qualquer coisa, isso não tem importância. É reconhecer que as coisas se ligam em outros lugares e, uma coisa importante, é que elas se deslindarão em outros lugares". Para o debate no seio do conjunto dos bairros, trata-se de recriar o elo social, a relação social, fator de "desdramatização" do cotidiano.

A ausência efetiva do ator central significa que todo mundo pode ser ator e, de um certo ponto de vista, é isso que confere um caráter "democrático" a esses espaços. Isso permite, igualmente, uma certa capacidade de agregar todos os cidadãos em torno dos desafios que não são puramente uma repetição do amálgama da estrutura de dominação, mas a recusa de todo poder acompanhado por uma vontade de fazer participar o conjunto da sociedade civil nas decisões que empenham seu futuro. Em outros termos, esses espaços têm sua eficácia no caráter fluído e indeterminado, na sua relativa pobreza ideológica, na sua indigência em utopia e na sua recusa de se institucionalizar. Esses espaços devem favorecer as formas de sociabilidade que dão consciência de participação na vida social. Deve resultar disso a sensação de participar de uma aventura coletiva. Reatamse, com os outros, relações que a monotonia da vida cotidiana e as transformações sociais segregativas haviam rompido.

Esses espaços devem dar oportunidades de se reconhecer semelhante aos outros, não por meio do consumo ou da publicidade, mas de maneira que cada um se sinta parte profundamente interessada em uma mobilização coletiva caracterizada pela convivialidade e pela confrontação com a alteridade.

Esses espaços são, pois, marcados por suas formas dispersas, difusas, heterogêneas, permitindo a reunião de contestações diversas. 0 que é sua fragilidade, mas também sua força.

Desse modo, em Montceau-les-Mines, a abertura para as organizações sindicais e políticas, que se impôs no momento da passagem

8. Jogo de palavras utilizado pelo autor que the permite mostrar as diversas facetas da vida. Envie, significa desejar e invejar; ené uma proposição utilizada em muitas locuções prepositivas; poderíamos traduzir en-vie de três formas, todas elas cabíveis nesse contexto: [coisas] de vida, desejos, invejas (N. da T.). 
dos "grupos de doentes" para os "grupos de bairro", teve necessidade de garantir que a experiência não se transformasse em simples plataforma reivindicativa. "Pode-se afirmar ainda que os grupos de reflexão sobre a saúde ${ }^{9}$ correm o risco de serem sempre perdedores ante as organizações políticas, visto que estas últimas são perfeitamente estruturadas, ao passo que [os grupos de bairro] se apresentam da maneira a menos institucional possível” (Mongin, 1978).

lsso não leva a pensar, relativamente a uma problemática social e cultural complexa cuja tradução no jogo político não é imediata, em outras formas de mobilização que não as encaminhadas pelas organizações sindicais ou políticas tradicionais? É esse o desafio dos espaços de debates!

Esses espaços de debates devem favorecer a passagem da expressão de uma situação à análise da sua produção. Parece-nos necessário ultrapassar o nível das práticas-respostas para nos voltarmos ao da produção conflitual de uma situação.

Do ponto de vista da análise e da ação dos atores da intervenção social ainda é a norma social que deve ser interrogada. Esses espaços devem permitir uma expressão das condutas individuais e coletivas que nunca estão em concordância com o conjunto das normas tomadas como tal. E é nessa desdramatização, nessa interrupção do tratamento da normalização, que poderá surgir um retorno aos questionamentos dos atores.

Passar da ordem das respostas ao movimento das questões!

É nessa tentativa delicada que, talvez, possa se ver desenvolvida, no nível local, uma possibilidade de limitar a decomposição social, a pequena delinqüência, a dependência em relação ao álcool, à droga, aos remédios, o sentimento de exclusão, as violências familiares, as violências interétnicas, intergeracionais. Esses espaços têm como objetivo permitir uma maior abertura à cidadania e à expressão dos conflitos sociais democraticamente geridos.
Espaços de debates para marcar a fronteira do que se torna intolerável, do que não pode mais ser aceito como humilhação no campo das relações sociais.

Espaços de debates para rejeitar todo poder que toma decisões sem negociar com o corpo social.

Espaços de debates para recusar a dualização da realidade social entre a integração e a exclusão.

Eis o desafio das novas modalidades de contestação coletivas.

A necessidade de debater sobre a construção coletiva do sentido, sobre a configuração da sociedade civil futura, encontra-se cada vez mais não realizada por falta de mecanismos sociais realmente adaptados a esse desafio. Convocar o conjunto dos atores ao comprometimento com o debate coletivo supõe interrogar-se sobre as modalidades de participação/ reivindicação das populações constituintes do tecido social.

Uma lógica da participação não pode ser pretendida sem espaços de debates que possam ver desenvolvidos as tensões, os conflitos, as aberturas e a necessária elaboração de um compromisso aceitável. É apenas favorecendo a criação de espaços de debates, nos quais o conjunto dos habitantes poderão tomar ou retomar em suas mãos seu destino, que é possível ter esperança em conter a dissociação das relações sociais e a explosão das condutas sociais marcadas pelo desespero e pela dependência agressiva ou mortífera.

É canalizando, no seio de espaços de debates, essas novas formas de participação ativa que se pode produzir relação social e regular as tensões sociais. No nível da ação, trata-se de construir um outro olhar que busca os "a mais" sobre os quais se possa sustentar uma modificação das perspectivas de ação.

Desse modo, as populações desfa-

9. Entendo o conceito de saúde de acordo com a definição dada pela Organização Mundial da Saúde: "um estado de completo de bem-estar físico, mental e social que não consiste unicamente na ausência de doença ou enfermidade". 
vorecidas, com residência definida pelo Estado, cativas da cidade, têm também capacidade de mobilidade e de mobilização. Por trás dos lugares de exclusão e de isolamento se perfilam lugares de misturas sociais, de trocas e de sociabilidade. É preciso, então, apoiar-se sobre redes de solidariedade e favorecer os movimentos esporádicos ou associativos nesses lugares, nesses bairros. É uma maneira de repensar a cidadania inclinando-se para as diferentes possibilidades de "viver junto". Mas esse "viver junto" não supõe a existência de espaços necessários à expressão de conflitos? Conviver não implica lugares de negociação, de oposição, de compromisso?

É necessário aumentar o conhecimento daqueles que "animam" os bairros, sabendo que eles não podem se reduzir aos únicos trabalhadores sociais e profissionais do campo sociocultural.

Pensamos nos professores, nos clínicos gerais, nos comerciantes, nos militantes de associações, nos funcionários dos Offices de logements, ${ }^{10}$ nos funcionários das administrações locais. Pensamos igualmente nos "papéis secundários" que são representados pelas pessoas mais idosas, pelas crianças e pelas mães que ficam em casa... Pensa-se, também, nos lugares imersos no cotidiano, os cafés, os locais de comércio que remetem à construção de espaços privados-públicos. Trata-se de recolocar no centro dos debates uma articulação entre as práticas cotidianas dos habitantes e as políticas locais estabelecidas. Trata-se de orientar-se na direção das questões da negociação em torno dessa cotidianidade e, por essa via, do controle da cidadania e do político.
Para construir uma perspectiva de ação, deixamos então de lado uma análise em termos de faltas e deficits para tentar uma abordagem que busca captar os processos em construção no cotidiano dos habitantes. Esses processos podem ser apreendidos em termos de sociabilidade no sentido do controle, pelo habitante, de seu espaço de vida, quer dizer, de retomar o lugar no político? Trata-se de produzir relação social em nome de uma cidadania a se reencontrar.

Como, então, posso comunicar-me como os outros e viver com eles? Como podemos combinar nossas diferenças com a unidade de uma vida coletiva?

As duas questões que sustentaram essa comunicação articulam-se nessa pergunta.

Por detrás da relação entre identidade integrativa e identidade conflitual desponta a construção do Sujeito definida como a vontade, a capacidade de cada indivíduo de participar ativamente e conflitualmente na criação da vida social. Do lugar onde estou, definido por orientações culturais, por relações sociais e um campo familiar e social de formação da personalidade, como posso ser criador, ou seja, participar da produção da sociedade que parece me determinar?

Quanto aos espaços de debates, eles favorecem a construção desse viver junto de iguais e diferentes, reconhecendo ao Outro, como a si mesmo, o direito de ser Sujeito e pondo a democracia a serviço da liberdade criadora de cada um e da construção de uma solidariedade coletiva.

10. Repartições públicas com a função de construir e financiar moradias populares. 


\section{Referências bibliográficas}

BENJAMIN, Walter. Magia e técnica, arte e política: ensaios sobre literatura e história da cultura. 7ae ed. Trad. Sérgio Paulo Rouanet.

BACHMAN, C. Une fonction sociale généralisée. Revue Esprit, Paris: n. 3-4, 1998.

DOLTO, F. La cause des enfants. Paris: R. Laffont,1985.

DUBET, F. La galère, jeunes en survie. Paris: Fayard, 1987.

Sociologie de l'expérience. Paris: Seuil, 1994.

DUBET, F.; MARTUCELLI, D. Dans quelle société vivons-nous? Paris: Seuil, 1998.

GAULEJAC, V de. ; TABOADA LEONETTI, I. La lutte des places. Paris: Desclée de Brouwer, 1994.

GOFFMAN, E. Stigmate, les usages sociaux des handicaps. Paris: Editions de minuit, 1975.

LAPEYRONNIE, D. La gauche face aux exclus. In : COLLOQUE DE CERISY, 1995, Paris. Penser le sujet. Paris: Fayard, 1995.

LUCAS, P. Une autre relation thérapeutique, l'expérience de Montceau-les-Mines. Revue Esprit, Paris, n. 4, 1978.

MANNONI, M. Un savoir qui ne se sait pas. Paris: Denoël, 1985.

MONGIN, O. L' expérience de Montceau-les-Mines. Revue Esprit, Paris, n. 4, 1978.

ROSOLATO, G. Recension du corps. Nouvelle Revue de Psychanalyse, Paris, n. 3, 1971.

SCATOLERO, D. Turin, l'ouverture de la prison à la ville. Que fait-on des délinquants à New York, Stockholm, Turin, Birmingham. Antenne 2, Paris, 28 avril 1985. (Série Sorties de Secours)

SCHALLER, J.-J. Pour une mobilisation de tous les acteurs ! In: AFCHAIN, J. Les associations d'action sociale. Paris: Dunod, 1997. . La personne en difficulté au cœur des politiques sociales. In: . Accompagner la personne en difficulté: politiques

sociales et stratégies de direction. Paris: Dunod, 1999.

TOURAINE, A. Face à l'exclusion, In : CITOYENNETÉ et urbanité. Paris: Editions Esprit, 1991.

Critique de la modernité. Paris: Fayard, 1992.

. La formation du sujet. In: COLLOQUE DE CERISY, Paris, 1995. Penser le sujet. Paris: Fayard, 1995.

. Pourrons-nous vivre ensemble, égaux et différents? Paris: Fayard, 1997.

Recebido em 10.06.2002

Aprovado em 05.09.2002

Jean-Jacques Schaller é professor na Universidade Paris 13, onde dirige 0 Institut Universitaire Professionnalisé ligado à Faculdade de Ciências da Educação. Escreveu uma tese sobre marginalidade e trabalho social. Como pesquisador, seu trabalho articula-se em torno de dois pólos: a ação das populações marginais e os sistemas de intervenção. 